\title{
Ergonomic Evaluation of Job Performance and Investigation of the Impact of Corrective Exercise Training on Reduction of Musculoskeletal Complaints Among Operating Room Nurses in Iran
}

Ali khani jeihooni

Fasa University of Medical Science

Tahereh Gholami ( $\nabla$ gholamitahereh@yahoo.com )

Fasa University of Medical Science https://orcid.org/0000-0001-5859-5260

Sedighe Omidi

Fasa University of Medical Science

Omalbanin Taheri

Fasa University of Medical Science

Azizollah Dehghan

Fasa University of Medical Science

\section{Research article}

Keywords: Musculoskeletal disorders, Ergonomics, Operating room nurses, Corrective exercises

Posted Date: December 2nd, 2020

DOI: https://doi.org/10.21203/rs.3.rs-116198/v1

License: (c) (1) This work is licensed under a Creative Commons Attribution 4.0 International License.

Read Full License 


\section{Abstract}

\section{Background}

Operating Room(OR) nurses are at risk of Musculoskeletal Disorders(MSDs) due to the nature of their job and performance of non-ergonomic activities. The present study aimed at ergonomic evaluation of the workplace and investigation of the impact of corrective exercise training on reduction of musculoskeletal complaints among OR nurses.

Materials and Methods

This educational intervention study was conducted on 46 OR nurses in an educational hospital in Fasa city in Iran. who were selected through census. Data were collected via demographic information form, body map, and Rapid Entire Body Assessment(REBA) method. After three months, the effects of ergonomic principles training and intensity of disorders were evaluated by the REBA method and body map respectively. After all, the data were analyzed using descriptive statistics, Wilcoxon test, and marginal homogeneity in SPSS $_{20}$ software.

\section{Results}

mean age and mean job tenure of the nurses were 28.93(6.47) and 6.02(5.62) years, respectively. $78.3 \%$ of the participants were male, $38 \%$, were single, and $91 \%$ were shift workers. a significant decline was observed in disorders in all body regions, except for the head and neck $(p=0.293)$, three months after the educational intervention. The mean score of the REBA test was $5.58 \pm 1.146$ after the intervention $(p=0.000)$. Additionally, the mean level of risk was $2 \pm 1.89$ after the intervention $(p=0.000)$. the mean level of corrective priorities was $1.0 \pm 89.314$ after the intervention $(p=0.000)$. the corrective actions reached levels 1 and 2 after the intervention. Accordingly, the highest percentage of actions for reduction of injuries were at the necessary (soon) level before the intervention, but at the necessary level after that $(89.1 \%)$.

Discussion and Conclusion

The results indicated that training ergonomic principles, correct goods transfer methods, and corrective exercises has been recommended to be effective in decreasing the risk of MSDs in this profession.

\section{Introduction}

Musculoskeletal Disorders (MSDs) are among the common causes of work-related injuries and disability in developing countries. They are also among the main reasons for referral to physicians, specialists' absence from work, and reduction of their life quality and productivity (1). The most common MSDs include low back pain, neck injuries, and shoulder and specular chronic inflammation. However, the high prevalence of these disorders can be considerably decreased in the workplace by carrying out low-cost ergonomic programs (2). Healthcare environments, such as hospitals, are among the occupations where 
individuals are at risk of disorders or injuries due to workplace risk factors. A high prevalence and incidence of physical disorders, including MSDs, has also been reported among healthcare staff (3). Operating Room (OR) nurses comprise a part of healthcare personnel in hospitals. The results of studies on OR nurses have indicated the frequency of shoulder pain and low back pain to be $58-90 \%$ in this occupational group (4-7). In addition, Choobineh et al. reported that low back pain was the most common MSD among OR nurses (5). Nützi et al. also conducted a study in 2015 and disclosed that $66 \%$ of OR nurses suffered from MSDs in various areas of their bodies (8).

In Iran, OR nurses play circulating or scrub roles in the OR. In the circulating role, the nurse monitors all stages of the procedure and is the connector between the environment and the sterile team. In the scrub role, the nurse as a member of the sterile team moves the surgical instruments and helps the surgeon in various stages of the operation. In fact, an OR nurse shifts between these two roles. In other words, an OR nurse plays the scrub role in one operation and the circulating role in another. Evidence has demonstrated that OR nurses are encountered with incorrect and long-term postures during surgical operations (9). Besides, most studies have reported the prevalence of low back pain, shoulder pain, and neck pain in both circulating and scrub roles (10). Advancement of technology and the resultant immobility as well as manual patient transfer require high physical demands and lead to postural problems and MSDs (11). In OR nurses also, performance of repeated, monotonous, and hasty tasks as well as remaining in improper body positions during surgical operations result in an increase in long-term static pressures. Dynamic pressures caused by pulling, pushing, or lifting heavy objects may also lead to MSDs, particularly in the back area (12). These disorders result in direct costs for diagnosis and treatment as well as indirect costs due to specialists' absence from work (13). Despite the spread of mechanized and automatized processes, work-related MSDs result from various multifaceted risk factors and lead to loss of working time, absence from work, increase in expenditures, and workforce injuries (14). These injuries have been considered to be among the main challenges that not only reduce the working time or lead to job change, but also exert harmful effects on physical and mental health, quality of life, and socioeconomic costs. Hence, they have been regarded as an occupational problem among healthcare staff (15).

Demographic, physical, and psychosocial factors have been shown to be effective in the incidence of musculoskeletal discomforts and their combination has been reported to increase the risk (16). In this respect, major demographic factors include age, sex, Body Mass Index (BMI), and smoking.

Organizational factors include physical factors, manual goods transfer, frequent bending and twisting, excessive force exertion, and inappropriate work status. Finally, psychological factors include high occupational demands, low control over one's job, and lack of social support $(17,18)$. Pain, in turn, leads to reduction of mobility, decrease of recreational activities, loss of appetite, and insomnia, eventually resulting in spending lots of money for its elimination (19).

Considering the increase in workload, physical risks in the $\mathrm{OR}$, and use of equipment without proper training and their effects on the personnel's health, the importance of ergonomic principles training in hospitals is quite evident. In the present study, the researchers aimed to train the OR personnel of Vali-eAsr Hospital in Fasa regarding the correct work postures and their impact on MSDs. Generally, managers 
imagine that the personnel are not highly at risk of work-related disorders and, consequently, pay more attention to patients' health (20). By ergonomic evaluation of the workplace using Rapid Upper Limb Assessment (RULA), Rapid Entire Body Assessment (REBA), Ovako Working Posture Analysis System (OWAS), etc. and training of correct working postures and ergonomic principles in lifting objects, MSDs can be decreased and their outcomes can be managed among nursing personnel, eventually leading to promotion of healthcare staff's health. This will in turn result in the increase of work quality and occupational performance, decline of the related costs, and considerable socioeconomic achievements. Based on what was mentioned above, the present study aims to:

1. determine the intensity of MSDs among OR nurses prior to the intervention,

2. determine the risk level and score of the REBA method among OR nurses prior to the intervention,

3. determine the intensity of MSDs among OR nurses after the intervention,

4. determine the risk level and score of the REBA method among OR nurses prior to the intervention, and

5. determine the effect of the educational intervention on reduction of MSDs among OR nurses.

\section{Methods}

This educational intervention study was conducted on 46 OR nurses in the hospitals affiliated to Fasa University of Medical Sciences selected through census from October 2017 to March 2018. The participants were entered into the research after completing written informed consent forms. It should be noted that only the nurses with more than one year of job tenure were enrolled. The individuals with the history of effective diseases in the musculoskeletal system and those with the history of suffering from MSDs were excluded from the study.

This study was conducted in four stages as follows:

First stage: Evaluation of musculoskeletal and ergonomic disorders among OR nurses prior to the intervention (targets 1 and 2)

Second stage: Training OR nurses with regard to corrective exercises

Third stage: Evaluation of musculoskeletal and ergonomic disorders among OR nurses after the intervention (targets 3 and 4 )

Fourth stage: Analysis of the evaluation results three months after the intervention (target 5).

First stage: Evaluation of musculoskeletal and ergonomic disorders among OR nurses

The nurses' postures were analyzed using a demographic information form, body map, and REBA method using the REBA software for Windows (for facilitating the task and improving the accuracy of evaluation). The demographic information form included 28 items about the nurses' personal and 
organizational characteristics (sex, age, height, weight, job tenure, number of children, education level, work plan, number of working hours per day, number of working hours per month, etc.).

Body map was used to assess the intensity and location of MSDs among nurses. In this instrument, the participants' opinions about pain could be determine via the Visual Analogue Scale (VAS).

The main issue regarding posture analysis is identifying the intended posture for assessment for which job analysis or task analysis has to be carried out. An observational technique for posture analysis is the REBA method, which was presented by McAtamney and Hignett in 1995. In this method, body regions are divided into groups A (trunk, neck, and feet) and B (arms, forearms, and wrists) for analysis. Then, body posture is analyzed based on body angles during work using the related tables.

Second stage: Training OR nurses with regard to corrective exercises and correct postures

After the initial assessments and identification of target regions, an educational team was created in order to measure the impact of training on the OR nurses. The training classes were conducted from 23 October 2018 for three months. In the first month, two training classes were held. Then, one training class was held each month in order to continue training with respect to work-related MSDs, correct patient transfer techniques, and exercises for prevention of low back pain. In addition, the participants were provided with booklets about ergonomic principles in the OR, manual goods transfer, and corrective exercises for improvement of low back pain.

\section{Third stage: Ergonomic evaluation of the OR three months after the training}

Three months after the training workshop, the impact of ergonomic principles training was assessed via the REBA method, body map, REBA risk level, and intensity of MSDs.

Fourth stage: Analysis of the evaluation results after the educational intervention

The data were entered into the SPSS 20 software and were analyzed using descriptive statistics, Wilcoxon test, and marginal homogeneity.

\section{Results}

The participants' personal and organizational characteristics have been presented in Table 1. Accordingly, the mean age and mean job tenure of the nurses were 28.93 (6.47) and 6.02 (5.62) years, respectively. Additionally, $78.3 \%$ of the participants were male, $38 \%$, were single, and $91 \%$ were shift workers.

Table 1. The participants' personal and organizational characteristics $(n=46)$ 


\begin{tabular}{|lll|}
\hline Age (years) & Mean (SD) & $28.93(6.47)$ \\
\cline { 2 - 3 } Job tenure (years) & Min-Max & $23-58$ \\
& Mean (SD) & $6.02(5.62)$ \\
\cline { 2 - 3 } Sex & Min-Max & $1-30$ \\
\hline Marital status & Male, $\mathrm{n}(\%)$ & $36(78.3 \%)$ \\
\cline { 2 - 3 } & Female, $\mathrm{n}(\%)$ & $10(21.7 \%)$ \\
\hline Education level & Single, $\mathrm{n}(\%)$ & $38(82.6 \%)$ \\
\cline { 2 - 3 } & Married, $\mathrm{n}(\%)$ & $8(17.4 \%)$ \\
\hline Second job & Bachelor's degree, $\mathrm{n}(\%)$ & $37(80.4 \%)$ \\
\cline { 2 - 3 } & Associate degree, $\mathrm{n}(\%)$ & $9(19.6 \%)$ \\
\hline Work system & Yes, $\mathrm{n}(\%)$ & $2(4.3 \%)$ \\
\cline { 2 - 3 } & No, $\mathrm{n}(\%)$ & $44(95.7 \%)$ \\
\hline Job change intention & Fixed shifts, $\mathrm{n}(\%)$ & $4(8.7 \%)$ \\
\cline { 2 - 3 } & Rotating shifts, $\mathrm{n}(\%)$ & $42(91.3 \%)$ \\
\cline { 2 - 3 } & Yes, $\mathrm{n}(\%)$ & $13(28.3 \%)$ \\
\cline { 2 - 3 } & No, $\mathrm{n}(\%)$ & $33(71.7 \%)$ \\
\hline
\end{tabular}

The intensity of MSDs among the participants before and after the educational intervention has been presented in Table 2. Accordingly, a significant decline was observed in disorders in all body regions, except for the head and neck $(p=0.293)$, three months after the educational intervention.

Table 2. The intensity of MSDs among the participants before and after the educational intervention $(n=46)$ 


\begin{tabular}{|c|c|c|c|}
\hline & Before the intervention & After the intervention & $\mathbf{P}$ \\
\hline & $M(S D)$ & $M(S D)$ & \\
\hline Head and neck & $2.15(1.21)$ & $2.04(0.89)$ & 0.293 \\
\hline Shoulders & $2.69(1.71)$ & $2.07(1.30)$ & 0.000 \\
\hline Back & $2.82(1.46)$ & $2.09(1.07)$ & 0.000 \\
\hline Elbows & $2.39(0.93)$ & $1.59(0.65)$ & 0.000 \\
\hline Low back & $6.86(1.55)$ & $5.41(1.39)$ & 0.000 \\
\hline Wrists/hands & $4.1(1.91)$ & $2.63(1.45)$ & 0.000 \\
\hline Thighs & $3.6(.92)$ & $2.52(.86)$ & 0.000 \\
\hline Knees & $6.36(1.42)$ & $5.78(1.42)$ & 0.017 \\
\hline Feet & $1.84(0.36)$ & $1.33(0.47)$ & 0.000 \\
\hline
\end{tabular}

The results of the REBA test before and after the intervention have been presented in Table 3 . The mean score of the test was $5.58 \pm 1.146$ after the intervention, which was lower compared to before the intervention. The results of Wilcoxon test revealed that the reduction in the mean score of the REBA test was statistically significant $(p=0.000)$. Additionally, the mean level of risk was $2 \pm 1.89$ after the intervention, which was lower in comparison to before the intervention. The results of Wilcoxon test showed that this reduction was statistically significant $(p=0.000)$. In other words, the risk levels changed into low and moderate levels after the intervention. Finally, the mean level of corrective priorities was $1.0 \pm 89.314$ after the intervention, which was lower compared to the baseline. The results of Wilcoxon test indicated that the reduction of the mean level of corrective priorities was statistically significant $(p=0.000)$. According to the results, the corrective actions were at levels 2 and 3 before the intervention, but reached levels 1 and 2 after that. As shown in Table 3, the results of marginal homogeneity test demonstrated a significant change in the level and time of the required actions for reduction of injuries. Accordingly, the highest percentage of actions for reduction of injuries were at the necessary (soon) level before the intervention, but at the necessary level after that (89.1\%).

Table 3. The results of the REBA method before and after the educational intervention 


\begin{tabular}{|c|c|c|c|c|c|}
\hline & $\begin{array}{l}\text { Before the } \\
\text { intervention } \\
\text { M+SD }\end{array}$ & $\begin{array}{l}\text { Before the } \\
\text { intervention } \\
n(\%)\end{array}$ & $\begin{array}{l}\text { After the } \\
\text { intervention } \\
\text { M+SD }\end{array}$ & $\begin{array}{l}\text { After the } \\
\text { intervention } \\
\mathrm{n}(\%)\end{array}$ & $P$ \\
\hline Final score & $8.0 \pm 09.626$ & & $5.1 \pm 58.146$ & & 0.000 \\
\hline Risk level & $2.0 \pm 91.285$ & & $1+2.89$ & & 0.000 \\
\hline Low & & - & & $5(10.9 \%)$ & \\
\hline Moderate & & $4(8.7 \%)$ & & $41(89.1 \%)$ & \\
\hline High & & $42(91.3 \%)$ & & - & \\
\hline $\begin{array}{l}\text { Corrective actions } \\
\text { priorities }\end{array}$ & $2.0 \pm 89.315$ & & $1 \pm 89.314$ & & 0.000 \\
\hline 1 & & - & & $5(10.9 \%)$ & \\
\hline 2 & & $5(10.9 \%)$ & & $41(89.1 \%)$ & \\
\hline 3 & & $41(89.1 \%)$ & & - & \\
\hline $\begin{array}{l}\text { Necessity and time } \\
\text { of actions }\end{array}$ & & & & & 0.000 \\
\hline Not necessary & & $0 \%$ & & $0 \%$ & \\
\hline May be necessary & & $0 \%$ & & $5(10 \%)$ & \\
\hline Necessary & & $6(13 \%)$ & & $41(89.1 \%)$ & \\
\hline Necessary (soon) & & $40(87 \%)$ & & $0 \%$ & \\
\hline $\begin{array}{l}\text { Necessary } \\
\text { (immediately) }\end{array}$ & & $0 \%$ & & $0 \%$ & \\
\hline
\end{tabular}

\section{Discussion}

This study aimed to investigate the effect of corrective exercise training on reduction of musculoskeletal complaints among the OR nurses of an educational hospital in Fasa, Iran. The results revealed the high prevalence of MSDs in various body regions of OR nurses. The highest intensities of these disorders were related to low back, knees, wrists, and hands prior to the intervention. Arsalani et al. used the Nordic questionnaire and reported that the highest 12-month prevalence of MSDs was detected in the low back, knees, and neck among Iranian nurses (21). Nützi et al. also made use of the German version of North American Spine Society (NASS) and stated that low back pain $(52.7 \%)$ and neck pain (38.4\%) were the most common musculoskeletal complaints among OR nurses (8). However, a decrease was observed in the pain intensity in the aforementioned regions after the training of ergonomic principles and corrective exercises. Low back injuries and the resultant pain are cause by damages to functional tissue units. In fact, functional tissue units help individuals bend, rotate, and twist. They also cause body weight to be 
well tolerated by the spinal cord (22). These tissues might be damaged among OR nurses due to difficult working conditions, spinal rotation, inappropriate body postures (excessive rotation and twisting), patient transfer, and long-term bending. Munabi et al. conducted a research on 880 nursing personnel and disclosed that low back injuries were caused by long-term and excessive bending of the low back as well as by transferring and pushing heavy goods (23). Moreover, Choobineh et al. (5) and Bos et al. (4) reported that OR nurses' prolonged working in standing position led to a high intensity of musculoskeletal symptoms in their knees. Furthermore, Surawera et al. used the Nordic questionnaire and reported that the one-month prevalence of wrist/hand pain was $15.3 \%$ among nurses (24). Wrist/hand pain among OR nurses might have its roots in the inappropriate design of OR equipment, prolonged and inappropriate use of the equipment, and improperly grabbing goods in manual transfer tasks. In order to compare the results of different studies, lack of standard methodologies, reporting methods, and cultural differences between the nurses working in Iran and other countries should be taken into consideration. It should be noted that body map was utilized to assess the intensity of musculoskeletal pains in the current study.

The findings of the research by Shiri et al. demonstrated that exercising reduced the risk of low back pain and its related disabilities. Thus, a combination of strengthening, stretching, and aerobic exercises twothree times a week was recommended to prevent low back pain in the general population (25).

The previous studies have proposed that low back pain might result from various reasons, including personal features (age, physical readiness), psychosocial factors (stress, anxiety, depression), and occupational factors (heavy physical work, rotation, twisting, vibration) (26). However, chronic low back pain is hard to be treated and many introduced interventions have been proved not to be effective (27). Rainville et al. stated that exercising could improve lumbar strength and flexibility and enhance the lumbar range of motion (28). In addition, Hoffman maintained that exercising was effective in prevention of depression and promotion of mood (29). Nonetheless, several studies have referred to the difficulty in the clinical execution of guidelines due to the variety of exercise interventions, simultaneous effects of interventions, contradictory suggestions regarding the intensity and duration of exercises, and insufficient information about the type of exercises (30-32). Hence, the role of exercising and the effects of particular exercises on improvement of low back pain are still unclear (33).

In the present study, ergonomic risk evaluation revealed that $91.3 \%$ of the OR nurses tolerated a high risk level prior to the intervention.

\section{Conclusion}

The study findings indicated the relatively high prevalence of MSDs among OR nurses. The results of risk level evaluation using the REBA method showed that both workplace conditions and task performance techniques were effective in the prevalence of these disorders. Considering the high frequency of improper body postures, inappropriate lifting and transfer of goods, and prolonged standing in the OR, corrective actions should be taken to reduce these disorders. Training of ergonomic principles, correct goods transfer techniques, and corrective exercises have been recommended to decrease the risk of 
MSDs in this profession. One of the study limitations was its educational intervention design. Hence, future randomized clinical trials are suggested to confirm the impact of corrective exercises on reduction of the risk of MSDs.

\section{Abbreviations}

Musculoskeletal Disorders (MSDs)

Operating Room (OR) nurses

Body Mass Index (BMI)

Rapid Upper Limb Assessment (RULA)

Rapid Entire Body Assessment (REBA)

Ovako Working Posture Analysis System (OWAS)

Visual Analogue Scale (VAS)

\section{Declarations}

\section{Ethical approval and Consent to participate:}

The participants were entered into the research after completing written informed consent forms and The research project related to the present article with the code of IR.FUMS.REC.1397.059 ethics was approved at Fasa University of Medical Sciences.

\section{Authors Contributions:}

Ali khani jeihooni $=\mathrm{A}$ kh

Tahereh Gholami $=$ TGh

Sedighe Omidi $=\mathrm{SO}$

Omalbanin Taheri $=0 \mathrm{~T}$

Azizollah Dehghan=A D

Mostafa Bizhani=M B

,Afsaneh Ghasemi=A Gh

"all authors have read and approved the manuscript", and ensure that this is the case. 
Acknowledgments

The authors would like to express their appreciation to all the administrative staff of the university for their cooperation in the study.

Funding: This study was funded by Fasa University of Medical Sciences (contract No. 97062).

\section{Competing interest:}

The authors declare no potential conflicts of interests with respect to the research \authorship and/or publication of this article.

\section{Availability of data and materials:}

The datasets used and/or analysed during the current study available from the corresponding author on reasonable request.

\section{References}

1. Anap DB, lyer C, Rao K. Work related musculoskeletal disorders among hospital nurses in rural Maharashtra, India: a multi centre survey. International Journal of Research in Medical Sciences. 2017;1(2):101-7.

2. Smith DR, Sato M, Miyajima T, Mizutani T, Yamagata Z. Musculoskeletal disorders self-reported by female nursing students in central Japan: a complete cross-sectional survey. International journal of nursing studies. 2003;40(7):725-9.

3. Tabatabaei S, Khani Jazani R, Kavousi Dolanghar A. Relationship between Musculoskeletal Disorders and Quality of Life in Employees of Selected Hospitals in Golestan Province. Journal of health research in community. 2017;3(1):45-56.

4. Bos E, Krol B, van der Star L, Groothoff J. Risk factors and musculoskeletal complaints in nonspecialized nurses, IC nurses, operation room nurses, and X-ray technologists. International archives of occupational and environmental health. 2007;80(3):198-206.

5. Choobineh A, Movahed M, Tabatabaie SH, Kumashiro M. Perceived demands and musculoskeletal disorders in operating room nurses of Shiraz city hospitals. Industrial health. 2010;48(1):74-84.

6. Sheikhzadeh A, Gore C, Zuckerman JD, Nordin M. Perioperating nurses and technicians' perceptions of ergonomic risk factors in the surgical environment. Applied Ergonomics. 2009;40(5):833-9.

7. van den Berg-Dijkmeijer ML, Frings-Dresen MH, Sluiter JK. Risks and health effects in operating room personnel. Work. 2011;39(3):331-44.

8. Nützi M, Koch P, Baur H, Elfering A. Work-Family conflict, task interruptions, and influence at work predict musculoskeletal pain in operating room nurses. Safety and health at work. 2015;6(4):329-37.

9. Bernard BP, Putz-Anderson V. Musculoskeletal disorders and workplace factors; a critical review of epidemiologic evidence for work-related musculoskeletal disorders of the neck, upper extremity, and 
low back. 1997.

10. Moscato U, Trinca D, Rega ML, Mannocci A, Chiaradia G, Grieco G, et al. Musculoskeletal injuries among operating room nurses: results from a multicenter survey in Rome, Italy. Journal of Public Health. 2010;18(5):453-9.

11. Mehta RK, Horton LM, Agnew MJ, Nussbaum MA. Ergonomic evaluation of hospital bed design features during patient handling tasks. International Journal of Industrial Ergonomics. 2011;41(6):647-52.

12. Daraiseh N, Cronin S, Davis L, Shell R, Karwowski W. Low back symptoms among hospital nurses, associations to individual factors and pain in multiple body regions. International Journal of Industrial Ergonomics. 2010;40(1):19-24.

13. Gonçalves MB, Fischer FM, Lombardi M, Ferreira RM. Work activities of practical nurses and risk factors for the development of musculoskeletal disorders. Journal of human ergology. 2001;30(12):369-74.

14. Choobineh A, Rajaeefard A, Neghab M. Association between perceived demands and musculoskeletal disorders among hospital nurses of Shiraz University of Medical Sciences: a questionnaire survey. International Journal of Occupational Safety and Ergonomics. 2006;12(4):40916.

15. Herin F, Paris C, Levant A, Vignaud M-C, Sobaszek A, Soulat J-M. Links between nurses' organisational work environment and upper limb musculoskeletal symptoms: Independently of effort-reward imbalance! The ORSOSA study. Pain. 2011;152(9):2006-15.

16. Wiitavaara B, Barnekow-Bergkvist M, Brulin C. Striving for balance: A grounded theory study of health experiences of nurses with musculoskeletal problems. International Journal of Nursing Studies. 2007;44(8):1379-90.

17. Ariëns GA, van Mechelen W, Bongers PM, Bouter LM, van der Wal Psychosocial risk factors for neck pain: a systematic review. American journal of industrial medicine. 2001;39(2):180-93.

18. Rafati N, Mehrabi Y, Montazeri A. Quality of life and its determinants in elderly people aged 65 and older residing in Tehran J Sch Public Health Instit Public Health Res. 2005;3:56-67.

19. Tsai Y-F, Tsai H-H, Lai Y-H, Chu T-L. Pain prevalence, experiences and management strategies among the elderly in Taiwanese nursing homes. Journal of Pain and Symptom Management. 2004;28(6):579-84.

20. Bhattacharya A. Costs of occupational musculoskeletal disorders (MSDs) in the United States. International Journal of Industrial Ergonomics. 2014;44(3):448-54.

21. Arsalani N, Fallahi-Khoshknab M, Josephson M, Lagerström M. Musculoskeletal disorders and working conditions among Iranian nursing personnel. International Journal of Occupational Safety and Ergonomics. 2014;20(4):671-80.

22. Azizpour Y, MaghsoodiMoghadam R, Delpisheh A. Ergonomic evaluation of job performance within the staff of the nursing and the operating room by reba technique. The Journal of Urmia Nursing and Midwifery Faculty. 2015;1(1):75-83. 
23. Munabi IG, Buwembo W, Kitara DL, Ochieng J, Mwaka ES. Musculoskeletal disorder risk factors among nursing professionals in low resource settings: a cross-sectional study in Uganda. BMC nursing. 2014;13(1):7.

24. Surawera IK, Hoe VC, Kelsall HL, Urquhart DM, Sim MR. Physical and psychosocial factors associated with wrist or hand pain among Australian hospital-based nurses. Injury prevention. 2013;19(1):13-8.

25. Shiri R, Coggon D, Falah-Hassani K. Exercise for the prevention of low back pain: systematic review and meta-analysis of controlled trials. American journal of epidemiology. 2017;187(5):1093-101.

26. Hall H, McIntosh G. Low back pain (chronic). BMJ clinical evidence. 2008;2008.

27. Bogduk N. Management of chronic low back pain. Medical journal of Australia. 2004;180(2):79.

28. Rainville J, Hartigan C, Martinez E, Limke J, Jouve C, Finno M. Exercise as a treatment for chronic low back pain. The Spine Journal. 2004;4(1):106-15.

29. Hoffman MD, Hoffman DR. Does aerobic exercise improve pain perception and mood? A review of the evidence related to healthy and chronic pain subjects. Current pain and headache reports. 2007;11(2):93-7.

30. Airaksinen O, Brox JI, Cedraschi C, Hildebrandt J, Klaber-Moffett J, Kovacs F, et al. Chapter 4 European guidelines for the management of chronic nonspecific low back pain. European spine journal. 2006;15:s192-s300.

31. Koes BW, van Tulder M, Lin C-WC, Macedo LG, McAuley J, Maher C. An updated overview of clinical guidelines for the management of non-specific low back pain in primary care. European Spine Journal. 2010;19(12):2075-94.

32. Swinkels A, Cochrane K, Burt A, Johnson L, Lunn T, Rees AS. Exercise interventions for non-specific low back pain: an overview of systematic reviews. Physical Therapy Reviews. 2009;14(4):247-59.

33. Searle A, Spink M, Ho A, Chuter V. Exercise interventions for the treatment of chronic low back pain: a systematic review and meta-analysis of randomised controlled trials. Clinical rehabilitation. 2015;29(12):1155-67. 